DOI 10.37882/2223-2982.2021.12-2.39

\title{
ТЕХНОЛОГИЯ В ПРЕПОДАВАНИИ ИНОСТРАННЫХ ЯЗЫКОВ
}

\section{TECHNOLOGY IN TEACHING FOREIGN LANGUAGES}

\section{Chango Andrango \\ L. Maltseva}

Summary: The article analyzes the technological resources of the university from the point of view of students, the participation of teachers in the preparation of didactic proposals using technology in teaching, which motivate students, which proves the importance of the participation of our university education system in improving the quality standards of teaching through the use of ICT in the process of teaching and language learning.

The emergence of ICT in the socio-cultural landscape has had a huge impact on the field of education in recent years, especially in the teaching of foreign languages. ICTs give the student the opportunity to practice all skills in real contexts of using the language being studied. This article will present all relevant aspects of ICT and foreign language teaching.

Keywords: education, technology, learning foreign languages, multimedia resources, mobile communication.
Чанго Андранго Диана Валерия

Аспирант, Краснодарский государственный институт культуры valerydn_82@hotmail.com

Мальцева Людмила Валентиновна д.п.н., доцент, Кубанский государственный университет

Аннотация: В статье анализируются технологические ресурсы университета с точки зрения студентов, участие преподавателей в подготовке дидактических предложений с помощью технологии в преподавании, которые мотивируют студентов, что доказывает важность участия нашей системы университетского образования в повышении стандартов качества преподавания посредством использования ИКТ в процессе преподавания и изучения языка. Появление ИКТ в социокультурном ландшафте оказало огромное влияние на сферу образования в последние годы, особенно в преподавании иностранных языков. ИКТ дают учащемуся возможность практиковать все навыки в реальных контекстах использования изучаемого языка. В данной статье будут представлены все актуальные аспекты ИКТ и преподавания иностранных языков.

Ключевые слова: образование, технологии, изучение иностранных языков, мультимедийные ресурсы, мобильная связь.
И зменения, происходящие в образовательно сфере, носят технический характер, поскольку мы меняем инструменты и материалы, с которыми работаем, но они также качественные, поскольку каждый образовательный контекст (будь то школа или университет) преобразуется с внедрением нового инструмента.

Опыт показывает нам, что при наличии технологических инструментов уровень знаний и навыков учащихся увеличивается. Эти инструменты действительно полезны, если они используются в соответствии с рациональными педагогическими подходами, учитывающими профессиональный опыт учителей и исследования в каждой области обучения. На сегодняшний день невозможно не внедрять технологии в обучение. В последние годы учителя имеют возможность наблюдать и участвовать в преобразовании различных областей системы образования посредством применения технологических ресурсов.

Онлайн образовательные ресурсы изменили способ взаимодействия и общения людей, они предлагают новые возможности и, как ожидается, повысят качество образования. Сценарии обучения направлены в новый формат, что является революцией в обучении в высших учебных заведениях.

Используя возможности обучения, предлагаемые ИКТ, например, онлайн-курсы, а теперь и дистанционное обучение, которые обещают новую методику препода- вания-обучения, сфера преподавания языка рассматривается как часть учебной деятельности, формирующая мост между субъектом и объектом изучения. К тому же, некоторые исследования показали его положительное влияние на мотивацию студентов к обучению, более того, согласно данным «Языкового барометра 2019», проведенного Бизнес-Институтом о привычках изучения второго языка, 37\% студентов считают, что Интернет является одним из лучших ресурсов для изучения языка. В отчете выводит заключение, что подавляющее большинство студентов знакомы с его использованием (часто используются мессенджеры, форумы, YouTube и электронная почта), что «способствует созданию чрезвычайно позитивной динамики в классе»).

Как следствие этого новшества, новые каналы коммуникации - особенно форумы, университетские платформы, электронная почта - являются инструментами, которые преподаватели должны использовать в качестве ключевого элемента всего учебного процесса. Однако отсутствие мотивации и доверия в их применении может стать препятствием для их успешного внедрения в языковой класс и другие предметы, преподаваемые в университете.

Эмоции и ИКТ в изучении языка - это аффективное измерение в образовательном процессе преподавания языка, которое начало признаваться в 1960-х годах с развитием гуманистической психологии. Начиная с этого 
момента, исследования, которые возникают об эмоции и познании показывают, что аффективное измерение не противопоставляется когнитивному измерению. В 1970x годах когнитивные психологи начали рассматривать и трактовать эмоции как существенный компонент когнитивной деятельности.

В начале 1980-х годов аффективное измерение уже принималось во внимание в области преподавания и изучения языка, например, естественный подход Крашена и Террела (1983) или коммуникативный подход, которые, хотя каждый это делал по-своему, уделяли особое внимание изучению взаимосвязи между познанием и эмоциями. В 1990-х годах многие психологи, лингвисты, неврологи и педагоги признали важную роль эмоций в обучении и пришли к консенсусу, что эмоции и познание являются двумя неразрывными компонентами в процессе обучения и поэтому должны изучаться вместе.

Общеевропейские компетенции владения иностранным языком CEFR (2002), которые начали формироваться в 1970-х годах, настаивают на необходимости учитывать опыт и потребности ученика, а не ориентировать обучение исключительно на лингвистические знания.

Об интересе общества к изучению эмоций свидетельствует успех работы Гоулмана «Эмоциональный интеллект» (1998).

Автор утверждал, что в процессе познания эмоции идут впереди разума, и что эти два понятия нельзя рассматривать отдельно, так как они неразрывно связаны. В области нейробиологии Le-Doux отстаивает идею о том, что «не может быть разума без эмоций».

Отсюда вытекает необходимость с детства обеспечивать привязанность и тепло, которые имеют трансцендентное значение в процессах обучения и приобретения знаний в целом. Подводя итог, можно сказать, что отсутствие эмоций усложняет сознательные способности, новый когнитивизм будет исходить из предпосылки, что мы можем изменить то, что мы чувствуем, изменив то, что мы думаем.

Хотя это может показаться парадоксальным, именно в эпоху новых технологий и больших научных достижений появляется растущий интерес к эмоциональному и аффективному измерению человека, причем настолько, что можно говорить об «эмоциональной революции». Последние достижения позволили распознать активность, взаимодействие и функционирование областей мозга в ответ на определенные стимулы или распознать нейронные механизмы, участвующие в различных процессах, например, в памяти. Мы сталкиваемся с цепным процессом, когда каждая часть мозга обуславливает другую; другими словами, если поражен ствол мозга (рептильный мозг), то это обуславливает лимбическую систему (мозг млекопитающих), а это обуславливает неокортекс (думающий мозг).

Мы считаем, что учителя должны знать о биологическом функционировании эмоций, чтобы создать оптимальный фон, способствующий обучению.

Например, стресс связан со стволом мозга. Студент, который испытывает тревогу, усталость, стресс или находится в любом другом состоянии, влияющем на эту часть мозга, не сможет легко учиться, как бы мы ни старались и сколько бы усилий он ни прилагал.

Следовательно, мы можем понять, что с самого первого момента человек учится в первую очередь благодаря эмоциональному интеллекту. Отсюда вытекает необходимость с детства обеспечивать привязанность и тепло, которые имеют трансцендентное значение в процессе обучения и приобретения знаний в целом.

Различные исследования, которые появляются в разных областях науки, говорят о том, что педагоги должны внедрять новые тенденции в образовательную практику. В конечном счёте, как утверждает ученый Гросс, все согласны с тем, что «мы можем ускорить и обогатить наше обучение, используя наши чувства, эмоции и воображение».

Сегодня никто не сомневается в том, что эмоции влияют на обучение, что они являются средством, которое может поддерживать, способствовать или блокировать этот процесс. Негативные эмоции могут препятствовать процессу обучения, а позитивные приносят удовлетворение от выполнения задания, развивая творческое мышление.

ИКТ начинают внедряться в языковой класс с использованием компьютера для отработки традиционного обучения, основанного на строгих и ограниченных упражнениях. В области преподавания и изучения языков интеграция ИКТ в учебный процесс началась в 1960-х годах, когда были использованы возможности «обучающих машин» - далеко идущего проекта по преподаванию предметов с помощью цифровых компьютеров. В 1970-х годах проводились глубокие исследования взаимодействия в коммуникации и структурирования содержания, но именно в 1990-х годах был достигнут наиболее быстрый прогресс с точки зрения технологических возможностей. Современное общество характеризуется использованием технологий, поэтому образовательные центры должны учитывать изменения.

Учителя и администрация должны прилагать усилия, чтобы идти в ногу со временем, адаптировать методики к технологическому прогрессу, но для того, чтобы пра- 
вильно управлять этой революцией, помогать ученикам, учителям необходимо постоянное обучение цифровой дидактике, чтобы с воодушевлением применять ее на практике. Развитие цифровой компетентности связано с эмоциями, которые порождают процесс преподавания и обучения, именно они направляют действия и выступают в качестве союза личности, соединяя мысли, суждения и убеждения людей, придавая смысл переживаниям.

Использование ИКТ, как мы уже упоминали, является одним из ресурсов, которые сейчас в большей степени внедряются во всех университетах мира в связи с пандемией Covid 2019.

Компьютер (Интернет, мультимедийные материалы, видеоконференции) был включен в качестве технологического инструмента, создавая таким образом виртуальные университетские кампусы.

Среди многочисленных польз для университетов стоит отметить следующие:

1. Преподаватель может легче разработать индивидуальную программу и привлекательный учебный материал для своих студентов.

2. Компьютер может избавить преподавателя от некоторых монотонных и утомительных задач, таких как, например, корректировка и маркировка теста с множеством вариантов.

3. Компьютер может выступать в роли наставника или партнёром для учащегося, даже когда учитель не присутствует рядом.

4. Компьютер быстро выполняет свои процессы и обеспечивает мгновенную обратную связь.

5. В то же время он терпелив, пока учащиеся думают и принимают решения; он не устаёт (повторяет столько раз, сколько необходимо).

6. Правильные программы мотивируют учащихся: привлекательная презентация, возможность контекстуализации (сочетание текста, звука и изображений), игровые возможности мультимедийного материала и так далее.

7. Компьютер обеспечивает доступ к аутентичным языковым образцам, содержащимся в лингвистических библиотеках; их можно использовать для представления моделей использования языка, разработки учебных заданий и т.д.

8. Интернет обеспечивает виртуальный, но прямой и реальный контакт с испаноязычным миром благодаря электронной почте, радиостанциям, телеканалам, газетам, журналам, библиотечным каталогам любой страны и т.д.; этот неисчерпаемый источник аутентичного и актуального лингвистического сырья значительно облегчает преподавание социокультурного компонента.

Зачем интегрировать ИКТ в учебный процесс?
«Интеграция ИКТ в преподавание языка представляет собой большой стратегический потенциал и дает ряд ощутимых возможностей для бюджетов и потребностей, о которых говорили с 1970-х годов в связи с коммуникативным методом и, совсем недавно, после публикации CEFR».

CEFR (Common European Framework of Reference for Languages, 2002) рассматривает изучающих язык как социальных агентов, которые, используя язык, должны уметь справляться с рядом коммуникативных ситуаций. Чтобы приобрести эту коммуникативную компетенцию, учащиеся должны проводить большое количество часов в контакте с целевой культурой и языком, взаимодействуя с другими носителями целевого языка.

Для учащихся, которые не могут или не хотят ехать в другую страну, новые технологии открывают доступ к пространствам для взаимодействия, информации и аутентичным материалам, которые в противном случае были бы им недоступны. CEFR устанавливает способность к обучению как одну из индивидуальных характеристик изучающего язык. В этом смысле ИКТ являются отличным вкладом, поскольку их потенциал способствует автономному обучению учащихся.

Важность включения цифровой компетенции в наши уроки сегодня неоспорима. Это позволяет нам работать в области, которая постоянно развивается, является гибкой и открытой для потребностей учащихся.

Интегрируя ИКТ в учебный процесс, мы можем организовать более интерактивный урок, в котором происходит не только информационный, но и культурный обмен.

Использование технологий позволяет нам открывать, анализировать и интерпретировать различные культурные и социальные представления о мире, в котором мы живем, с коммуникативной, социальной и коллективной точки зрения. Одно из огромных преимуществ ИКТ заключается в том, что они позволяют сделать занятия более персонализированными. Это необыкновенный инструмент для учителей. Использование интерактивных средств должно расширять возможности учащихся в процессе обучения, помогая им решать проблемы, принимать решения и искать данные, необходимые для выполнения задания.

Посредством различных ресурсов для урока, все они являются онлайн- материалами, доступными для педагогического сообщества: интернет, с тремя основными форматами: блоги, википедия и подкасты.

Блог поощряет участие и дебаты среди студентов. Блог ученика позволяет учителю и ученику следить друг 
за другом. Их можно использовать как личные дневники обучения или как портфолио, демонстрирующее прогресс ученика. Этот тип ресурса имеет множество педагогических возможностей. Учитель может предлагать задания, включать в них задания или даже проводить дискуссии. Они подчеркивают процессы и создают реальные ситуации общения.

Википедия поддерживает конструктивистскую модель обучения и выходит за рамки практики письменного изложения. Одной из важнейших особенностей Википедии является то, что она позволяет нам иметь историю изменений в ней.

Если мы используем Википедию на уроке, она будет полезна для: создания коллективных заметок, создания групповой работы, создания портфолио ученика или класса, координации распределения заданий для любого вида совместной работы, рецензирования работы ученика или группы, координации работы с учениками из других центров, работы над исправлением ошибок.

Подкастом мы называем набор аудиофайлов, которые доступны в Интернете, могут быть загружены и имеют подписку. Вы также можете получить образцы интервью и затем провести моделирование с учащимися (www.cadenaser.com/podcast). Тренируйте произношение (например, читая стихотворение или отрывок). Записывайте устные выступления учащихся. Проводите коммуникативные языковые мероприятия (устное и письменное понимание и выражение) и закрепляйте языковое содержание.

Аудиокниги: их можно скачать все виды носителей для чтения. Учителя могут использовать их для разработки дидактических последовательностей в соответствии с конкретными языковыми целями, предлагать их в качестве упражнений для отработки произношения или для обучения культуре.

Если мы правильно используем эти ресурсы в классе, мы будем способствовать развитию у учащихся понимания речи на слух, поможем работать над произношением и фонетикой на уроке, будем работать с уникальным материалом, развивать самостоятельное обучение и взаимодействие между учащимися.

ИКТ - это не методика и не сама цель на уроке иностранного языка, а инструмент в процессе преподавания и обучения. Они нуждаются в дидактическом подходе. Их вклад в прогресс учащихся будет зависеть от того, как мы включим их в программы. Внедрение ИКТ в учебный процесс требует инвестиций как с экономической точки зрения, так и с точки зрения времени, необходимого для обучения и подготовки новых материалов, поэтому их использование всегда должно быть оправданным.
Общие характеристики деятельности ИКТ для обучения:

1. развитие коммуникативных навыков изучаемого языка;

2. уникальность и коллективное участие;

3. поощрение самостоятельности учащегося;

4. поощрять сотрудничество между учениками;

5. принимать во внимание различные стили обучения и потребности учащихся;

6. использовать инструменты и технологии в обучении естественным образом;

7. включать процесс создания информации;

8. использовать различные языки;

9. должны быть адаптированы к уровню цифровой компетентности обучающихся.

В последние годы роль преподавателя иностранного языка претерпела значительные изменения. Если учитель хочет быть активным и новатором в этой области, он должен быть в состоянии подготовить учащихся к тем вызовам, с которыми они столкнутся в этой сфере. Роль преподавателя в изучении нового языка является основополагающей для достижения и усвоения языка учащимися. Мы должны помнить, что именно учитель сопровождает и направляет учащихся в процессе обучения. С помощью технологий произошли изменения, которые очень полезны для наших учеников, так как они направлены на развитие и самостоятельность домашних заданий. Учителя должны активно работать на уроке, всегда иметь четкие цели и стратегии, чтобы процесс обучения проходил индивидуально.

\section{Зак^ючение}

Внедрение ИКТ привело и продолжает приводить к важным изменениям в преподавании и изучении языков и, в частности, иностранных языков. Технология всегда должна быть включена в процесс обучения. Она помогает нам стимулировать учащихся не только на уроке, но и за его пределами. Новые программы и их использование предоставляет возможности для мотивации учащихся. ИКТ способствует активному обучению, основанному на опыте. Как преподаватели мы должны выбирать правильные виды деятельности и ресурсы для занятий иностранным языком таким образом, чтобы это было полезно и учащимся, и учителям. Учащиеся будут привлечены и мотивированы к анализу, исследованию и решению проблем, представленных им в динамичной и интерактивной форме с использованием новых ресурсов. Таким образом, мы добьемся более плодотворной и интерактивной работы в классе.

Использование ИКТ позволяет учащемуся начать обучение более самостоятельно. Оно способствует процессу изучения языка, который всегда требует длительных и постоянных усилий со стороны учащегося, и адаптируется к индивидуальному темпу обучения каждого учащего- 
ся. Он развивает, прежде всего, навыки понимания устной и письменной речи, пополнение словарного запаса и помогает улучшить произношение учащихся.
В заключение можно сказать, что использование ИКТ повысило качество преподавания иностранных языков.

ЛИТЕРАТУРА

1. Biasutti, Michele, Опыт студентов в совместном университетском модуле электронного обучения. Компьютеры и образование том 57 № 3: $1865-1875$. Elsevier B.V., 2011.

2. Арнольд, Джеймс, Аффективное измерение в изучении языка. - Кембриджского университета, Мадрид (Испания), 2000.

3. Бакс, Стивен, CALL - прошлое, настоящее и будущее. Система. №. 31: 13-28 n Elsevier B.V, 2002.

4. Бискверра, Рафаэль, La competencia emocional. В Руководстве по ориентации и преподаванию. Альварес Мануэль и Бискерра Рафаэль. 69-83. Праксис: Барселона, 2002.

5. ИНь, Хун Бяо и ЛИ, Джон Чи Кин. Будьте увлечены, но также будьте разумны: эмоциональные правила для работы учителя китайского языка. Преподавание и педагогическое образование. № 28 C.56-65. Elsevier B.V., 2012.

6. Лопес Вилчес, S, (2014) Оценка TFM веб-сайтов, специализирующихся на онлайн- обучении языкам, Университет Хаэн, 2014.

7. Мартин Монье, Э. Настоящее и будущее компьютерного обучения языкам: конец новой эры? Журнал лингвистики и прикладных языков, вып. 7, С.1-10, 2012.

8. Ревуэльта Домонгес Игнасио. Субъективное благополучие перед лицом хорошей образовательной практики с ИКТ: его влияние на новаторских учителей. Образование XXI. T. 16. № 1: 255-280. Факультет образования - UNED, Мадрид (Испания), 2013.

9. Себриан Мануэль и Санчес, Хулио, Влияние проекта по созданию центров ИКТ в начальных и средних школах Андалусии с точки зрения учителей. РіхеІBit Magazine, № 31: 141-154. Университет Севильи, Севилья (Испания), 2008.

10. Эрнандес Мерседес, М., Интеграция ИКТ в классе ELE. Панорама революции, Международный журнал иностранных языков, С. 63-99, 2012.

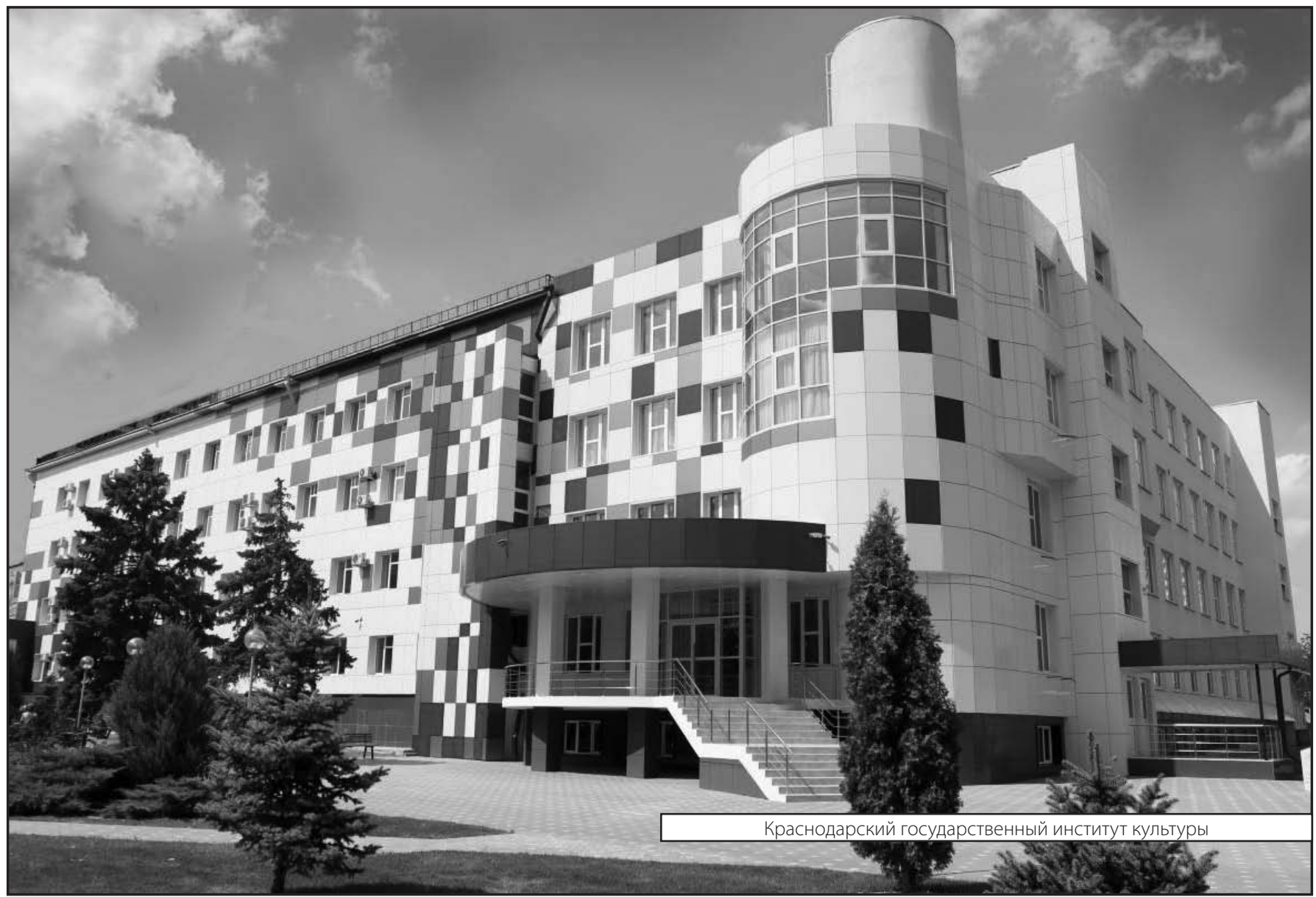

